\title{
A high-resolution and harmonized model approach for reconstructing and analysing historic land changes in Europe
}

\author{
R. Fuchs ${ }^{1}$, M. Herold ${ }^{1}$, P. H. Verburg ${ }^{2}$, and J. G. P. W. Clevers ${ }^{1}$ \\ ${ }^{1}$ Laboratory of Geoinformation Science and Remote Sensing, Wageningen University, Droevendaalsesteeg 3, 6708 PB \\ Wageningen, the Netherlands \\ ${ }^{2}$ Institute for Environmental Studies, VU University Amsterdam, De Boelelaan 1085, 1081 HV Amsterdam, the Netherlands \\ Correspondence to: R. Fuchs (richard.fuchs@wur.nl)
}

Received: 20 August 2012 - Published in Biogeosciences Discuss.: 25 October 2012

Revised: 13 February 2013 - Accepted: 13 February 2013 - Published: 7 March 2013

\begin{abstract}
Human-induced land use changes are nowadays the second largest contributor to atmospheric carbon dioxide after fossil fuel combustion. Existing historic land change reconstructions on the European scale do not sufficiently meet the requirements of greenhouse gas (GHG) and climate assessments, due to insufficient spatial and thematic detail and the consideration of various land change types. This paper investigates if the combination of different data sources, more detailed modelling techniques, and the integration of land conversion types allow us to create accurate, high-resolution historic land change data for Europe suited for the needs of GHG and climate assessments. We validated our reconstruction with historic aerial photographs from 1950 and 1990 for 73 sample sites across Europe and compared it with other land reconstructions like Klein Goldewijk et al. (2010, 2011), Ramankutty and Foley (1999), Pongratz et al. (2008) and Hurtt et al. (2006). The results indicate that almost $700000 \mathrm{~km}^{2}(15.5 \%)$ of land cover in Europe has changed over the period 1950-2010, an area similar to France. In Southern Europe the relative amount was almost $3.5 \%$ higher than average $(19 \%)$. Based on the results the specific types of conversion, hot-spots of change and their relation to political decisions and socio-economic transitions were studied. The analysis indicates that the main drivers of land change over the studied period were urbanization, the reforestation program resulting from the timber shortage after the Second World War, the fall of the Iron Curtain, the Common Agricultural Policy and accompanying afforestation actions of the EU. Compared to existing land cover reconstructions, the new method considers the harmonization of different datasets by achieving a high spatial resolution
\end{abstract}

and regional detail with a full coverage of different land categories. These characteristics allow the data to be used to support and improve ongoing GHG inventories and climate research.

\section{Introduction}

Human-induced land use changes (e.g. from deforestation) are nowadays the second largest contributor to atmospheric carbon dioxide after fossil fuel combustion (Van der Werf et al., 2009). For earlier decades (before 1960) the contribution of land change emissions to total emissions was even higher because of lower fossil fuel emissions (Brovkin et al., 2004; Houghton and Hackler, 2001; House and Prentice, 2002; Prentice et al., 2001). However, a large uncertainty in those assessments is presently due to the varying anthropogenic and natural land change processes going on in parallel (Houghton et al., 2012). A main shortcoming in making an assessment of the consequences of land cover change for climate and greenhouse gas (GHG) balances is the lack of spatially explicit and thematically complete historic high resolution land cover change data and its conversion types that feed into these models. This historic information on land cover is needed for GHG assessments, since every current land cover type also contains the legacy of previous land cover types, such as soil carbon from residues (Houghton et al., 2012; Poeplau et al., 2011). The consideration of this information may have a huge effect on the GHG estimation (Poeplau et al., 2011). Moreover, the information is needed for GHG models to deal with parameters 
like vegetation structure. Unless better base observations are available, the accuracy of GHG assessments will remain limited when based on uncertain data and methodologies (Ciais et al., 2011; Schulze et al., 2010). High-resolution and validated long-term consistent time series of land changes and their conversion types are fundamental to appropriately address potential error sources in GHG modelling, like scaling issues, management practices (e.g. tillage, $\mathrm{N}$-fertilizer) or information on the legacy of soil organic carbon after land conversion (Ciais et al., 2011; Gaillard et al., 2010; Poeplau et al., 2011; Schulp and Verburg, 2009; Schulze et al., 2010).

In recent years, significant progress in the gathering of historic land change data and reconstructions has been made by several authors, both at global and at continental scales. This includes the work of Klein Goldewijk et al. (2010, 2011), Ramankutty and Foley (1999), Pongratz et al. (2008), Hurtt et al. (2006), Olofsson and Hickler (2008) and Kaplan et al. (2009) (Table 1). Most of these are made for long time spans (several centuries to millennia) at broad geographic scales with limited spatial detail and not accounting for regional differences in land transition processes. For assessments at the continental scale, the current data have limitations regarding the spatial, temporal, and thematic resolutions for the periods they cover (Gaillard et al., 2010). The spatial resolution of existing data sets is not high enough to study land change patterns at continental and regional scale. The time steps of existing land data sets are often not consistent. This inconsistency makes it difficult to analyse ongoing processes like reforestation or cropland abandonment continuously over several decades. Moreover, existing land reconstructions focus primarily on just a few classes (e.g. cropland, pastures, population). None of the data sets offers a full land balance. This lack is problematic since certain change patterns cannot be fully observed. Although land categories like settlements, inland water and other land comprise only a small proportion of the full land cover (ca. 8-10\%), it is important to consider these classes in a land balance, as they are accounted otherwise to classes like forests, cropland or grassland. By not considering a full land balance, previous land reconstructions ignore competing land categories (since only $100 \%$ of the land area is available) and land conversion types (e.g. from cropland to settlement). For Europe these shortcomings appear in the same way. Since the EU reporting is on an advanced level for GHG emissions, there is a growing demand for high-resolution, harmonized and spatially explicit land change products, to improve our understanding of the amount and extent of human-induced land change processes (global and regional) (Ciais et al., 2011; Gaillard et al., 2010; Schulze et al., 2010).

At the same time, more detailed historic land use reconstructions based on real data (such as historic maps and remote sensing) have been gathered for local case studies or small regions (e.g. Antrop, 1993; Čarni et al., 1998; Bicik et al., 2001; Petit and Lambin, 2002; Van Eetvelde and Antrop, 2004, 2009; Kuemmerle et al., 2006; Orczewska,
2009). Such studies are able to describe land conversion patterns at a fine spatial, temporal and thematic detail and on the level where human-induced change processes take place. However, they are difficult to compare and combine with each other, especially cross-border. On a continental level their synergistic use will remain limited, due to a lack of an accepted and commonly used reporting scheme for land use classes, including standardized definitions and harmonization levels, but also as a result of their limited spatial coverage and focus on regions that are often known for large historic changes.

Many land transitions in Europe have taken place, affecting the land use pattern due to changes in farming or management systems (e.g. fallow land, abandoned, reactivated and reforested land). These changes follow fine-scale variability in environmental conditions, socio-ecological factors (such as demographic change), accessibility and cultural factors (Kuemmerle et al., 2009; Mander and Kuuba, 2004; Pinto-Correia and Vos, 2004; Prishchepov et al., 2012). Thus, they require high resolution data sets to observe and study these local heterogeneous processes. These changes may have large consequences for GHG emissions and climate variables (e.g. albedo) together with European-specific determinants that are crucial (e.g. management practices) (Houghton et al., 2012).

Based on the shortcomings of current land cover reconstructions and the needs of GHG and climate assessments, the objective of this study is to investigate if the combination of different and new data sources, detailed region-specific modelling techniques, and the consideration of multiple land cover types allows us to reconstruct historic land change for Europe at a high spatial resolution for the period 1950-2010. Therefore, we will focus on allocating existing harmonized land cover change data (see Sect. 2.2.1) rather than modelling these changes based mainly on assumptions for change processes. Validation with independent data and comparison with comparable land cover reconstructions is used to evaluate the research objective.

After presenting the methods employed to reconstruct historic land changes, this paper will analyse the regional land change hotspots over the 1950-2010 period and its major conversion types at the continental scale. The results will be compared with existing global-scale, historic land change databases of Klein Goldewijk et al. (2010, 2011), Ramankutty and Foley (1999), Pongratz et al. (2008) and Hurtt et al. (2006), henceforth referred to as Goldewijk, Ramankutty, Pongratz and Hurtt, respectively. Finally, the validation and performance assessment with independent historic high-resolution data (aerial photographs from 1950 and 1990) will outline uncertainties in our allocation of land cover and its changes on a pixel level. 
Table 1. Examples of geographically explicit studies of historical land cover/use, suitable for a Europe-wide assessment.

\begin{tabular}{|c|c|c|c|c|}
\hline Author/Dataset & $\begin{array}{l}\text { Spatial } \\
\text { Coverage }\end{array}$ & $\begin{array}{l}\text { Temporal } \\
\text { Coverage }\end{array}$ & Thematic Coverage & Spatial resolution \\
\hline Ramankutty and Foley (1999) & Global & $\begin{array}{l}1700 \mathrm{AD} \\
\text { to present }\end{array}$ & Cropland Pastures & $\begin{array}{l}0.5 \text { degree fractions and } \\
5 \text { arc minutes fractions }\end{array}$ \\
\hline Hurtt et al. (2006) & Global & $\begin{array}{l}1700 \mathrm{AD} \\
\text { to present }\end{array}$ & Cropland Pastures & 0.5 degree \\
\hline Olofson and Hickler (2007) & Global & $\begin{array}{l}4000 \mathrm{BC} \\
\text { to present }\end{array}$ & $\begin{array}{l}\text { Permanent agriculture } \\
\text { Non-permanent agriculture }\end{array}$ & 0.5 degree \\
\hline Pongratz et al. (2008) & Global & $\begin{array}{l}800 \mathrm{AD} \\
\text { to present }\end{array}$ & $\begin{array}{l}\text { UMD classes } \\
\text { (w/o Settlements) }\end{array}$ & 0.5 degree \\
\hline Kaplan et al. (2009) & Pan-European & $\begin{array}{l}1000 \mathrm{BC} \\
\text { to } 1850\end{array}$ & Forests & 5 arc minutes \\
\hline Klein Goldewijk et al. $(2010,2011)$ & Global & $\begin{array}{l}1700 \mathrm{AD} \\
\text { to present }\end{array}$ & Cropland Pastures & $\begin{array}{l}0.5 \text { degree for classes } \\
5 \text { arc minutes for fractions }\end{array}$ \\
\hline
\end{tabular}

\section{Data and methods}

\subsection{Overview of the method}

This study uses a land change quantity and land change allocation approach. The approach simulates land conversions on the basis of land change pressures, resulting from area statistics on country level for each land category (land change quantity), and allocates this information based on data that are able to indicate pixels of this land category where these changes are likely to happen (land change allocation). The preparation of the land change quantity data is explained in Sect. 2.2, the pre-processing of data for the land change allocation procedure in Sect. 2.3. The processing steps and the usage of the two data stacks are described in Sect. 2.4. To validate the performance of our approach, the results were compared with high-resolution aerial photos (1950 and 1990) obtained for regional case studies. This is presented in Sect. 2.5. The resulting data set of this investigation is called HIstoric Land Dynamics Assessment (HILDA).

\subsection{Harmonization and aggregation of data sources - land change quantity}

\subsubsection{Data sets and preparation}

Focus of this work will be on EU27 + Switzerland, since the data for these countries are quite good, even on regional scales (spatially, thematically and temporally). For this study the following land cover data sets (with national-level time series) were used for all EU-27 states plus Switzerland: CORINE for 1990, 2000 and 2006 (EEA, 2012); GlobCorine for 2005 and 2009 (ESA, 2011); UMD land cover classification (reference year 1991) (Hansen et al., 1998, 2000); Eurostat from 1974 to 2007 (European Commision, 2012); FAOSTAT from 1961 to 2008 (FAO, 2012a); FAO-FRA for 1946, 1953, 1958, 1963, 1976, 1985, 1990, 1992, 2000, 2005 and
2010 (FAO, 2012b); population statistics by Lahmeyer from 1950 to 2010 (Lahmeyer, 2006).

While remote sensing products could provide spatially explicit land cover and use information and its changes, it temporally covers only a relatively small proportion of the investigated time frame (1990s-2010 vs. 1950-2010). Some statistics instead span longer terms and some even the complete period. However, they are often just available as aggregated numbers on country scale and lack the information on spatial allocation within these administrative boundaries (Verburg et al., 2011).

For recent years (from 1990 onwards) the data availability and quality (temporal, spatial and thematic) is appropriate to cover major land changes in Europe. Remote sensing data can be used for the spatial allocation of land cover classes and for cross calibration of temporal land change trends with spatially coarse national statistics. Thus, the period 1990 2010 is used to intercalibrate the existing data sources and extrapolate the change trends using the less detailed data for the historical periods back to 1950 .

The various data do not necessarily follow the same nomenclature and class definitions have to be harmonized and aggregated to make them comparable. Besides the detailed analysis of existing legends (Herold and DiGregorio, 2012), the main idea was to aggregate to broad land categories in order to avoid definitional conflicts. In line with GHG accounting and climate modelling requirements, five suitable land categories were defined for the modelling:

- Settlements (incl. green urban areas),

- Cropland (incl. orchards and agro-forestry),

- Grassland (incl. natural grassland, wetlands, pasture and Mediterranean shrub vegetation),

- Forest (incl. transitional shrub and woodland, tree nurseries, reforested areas for forestry purposes) and 
- Other Land (incl. glaciers, sparsely vegetated areas, beaches and water bodies).

These classes and their definitions cover $100 \%$ of the land area in Europe and are based on the Intergovernmental Panel on Climate Change (IPCC) categories (IPCC, 2003). However, due to the lack of sufficient land information for the last $60 \mathrm{yr}$ of the wetland category, it was integrated in the grassland category.

The Land Cover Classification System (LCCS) (DiGrigorio and Jansen, 2000) was used to harmonize all existing data sets on the five IPCC classes. An overview of the class accounting and parameter description by LCCS is given in Appendix A. The advantage of this procedure is an objective class accounting using describable and comparable class features, instead of subjective appraisals.

\subsubsection{Data adjustment and analysis of land change trends}

The finest scale for a cross comparison along the data sets was the country scale, so all harmonized data were brought on that level for the analysis of land change trends. Spatially explicit data were geo-referenced on an equal area projection (Lambert Equal Area) to compare areas. Despite the harmonization process, the data sources could still differ in the overall amount of land cover area per class, e.g. due to the relatively coarse spatial resolution of GlobCorine $(300 \mathrm{~m})$ and UMD $(1 \mathrm{~km})$ or due to the fixed thematic boundary of some statistical classes. It was also recognized that in the Forest Resource Assessment (FRA) reports for Mediterranean countries like Spain, in some years shrublands were attributed to forests and in other years to cropland and grassland. In these cases other data sets, for example FAOSTAT, could be used instead.

The FAO-FRA data set provides cropland and grassland back to 1946. In comparison with FAOSTAT data (back to 1961), where these two classes are separated, area relations of these two classes and their relative trends over time could be calculated for each country. This allowed the separation of the FAO-FRA cropland and grassland class before 1961 .

Since settlement data were not separately reported in the statistics data (mainly included in settlement and others FAO or other land and settlements - FRA), population data and CORINE of the year 2000 was used to calculate the occupied settlement area per person in $\mathrm{m}^{2}$. This factor for each individual country could then be applied for all years of population data to estimate the area changes in settlements. Although we see this assumption as very simple and pragmatic, it turned out to be best practices compared to the otherwise required effort and its impact on the final results. Examples of $25 \%$ change in population density showed that most of the countries were only affected by less than $1.5 \%$ of area change (see Appendix D). By the use of the processed settlement areas, the other land class component could be extracted as residual.
For all countries and its land categories, outliers were sorted out and gaps with missing data were filled. An overview of the used method per country, per class and per year is given in Appendix B. Available data, which could be used for this study, were inter- and extrapolated by the use of approximation functions that were able to describe the land change trends over the whole period. The chosen polynomial order for each class per country is also given in Appendix B.

Due to the heterogeneous data sources, the sum of all harmonized land categories may lead to varying total areas per country over time. These differences occur, if the land categories are subject to high variances in area along the used data sets at one time step. For the investigated land categories, the variances were highest for grassland and lowest for settlements and forest. Reasons for these variances might be remaining inhomogeneity of class definitions and inaccuracies in classification of the products itself. To correct for discrepancies between the total area per country and the sum of all land categories, the one with the highest variance, in this case grasslands, was used to match the sum of all land categories with the total area per country. This step introduced a bias in the grassland estimates. However, the bias is very small (ca. 1\%) as compared to the overall uncertainty in the grassland category. By tuning the final reconstruction results to reported national quantities, all errors identified are basically location errors. The spatial allocation of land classes is validated using aerial photographs (see Sect. 2.5).

\subsection{Spatial distribution procedure - land change allocation}

A simple allocation procedure was implemented to distribute the land areas within the administrative boundary to $1 \mathrm{~km}^{2}$ pixels based on probability maps for each land category (Fig. 1). Probability maps represent the spatially explicit likelihood of a dominating land cover. The probability maps are derived through an empirical analysis of the relations between observed land use patterns in the year 2000 and a range of supposed explanatory factors conducted by Verburg et al. (2006) and Verburg and Overmars (2009) for the purpose of parameterizing a forward-looking land change model. Land use patterns in 2000 reflect the effect of a longer history of land change in response to biogeophysical and socio-economic conditions. As explanatory factors, Verburg and Overmars (2009) used biogeophysical factors with parameters like soil properties, precipitation, sunshine hours, altitude, slope, and socio-economic factors involving accessibility to settlements based on settlement size and population density. Logistic regressions were estimated for all land cover types and countries separately, allowing different variables to explain different land cover types across the different countries. Then, the probability of finding the land cover type under the prevailing conditions was calculated for all locations on a $1 \mathrm{~km}$ grid. The resulting probability maps are visualized in Fig. 1. Other Land was not processed since it is 


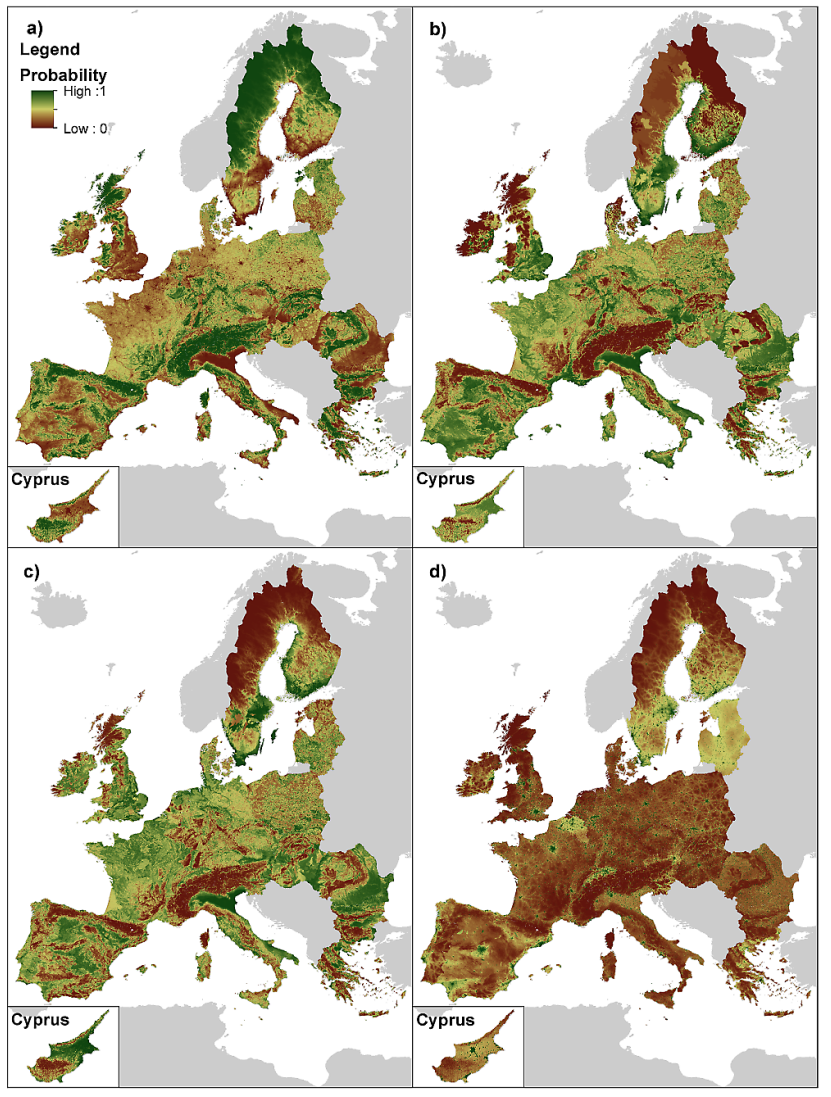

Fig. 1. Probability maps for each land cover class (forest a, cropland $\mathbf{b}$, grassland c, settlement d) calculated based on regression analysis conducted by (Verburg and Overmars, 2009). High probability values are in green, low probability values are in red. The Other land class has no probability map, because it is treated differently.

treated differently in the approach than the other classes (see Sect. 2.4).

Although the influence of some of the allocation factors on the probability maps may vary in time (e.g. population density and accessibility), most of the allocations remain stable over longer time periods (e.g. climate, terrain, soil factors). The impact of varying factors on the final data set was considered low and quantified in Sect. 2.2.2. Since this approach focusses mainly on input from land change data, many otherwise used allocation factors, such as management (e.g. major mechanization trends, strong increase in chemical fertilizers use, drastic decrease in labour force, different EU accession dates, etc.) are incorporated in the land demand part (so the statistics). For example, mechanization and increase of fertilizer use in agriculture led to less demand in cropland area due to higher yields. This decrease in demand can already be seen in almost every European cropland statistic, of which this approach makes use.

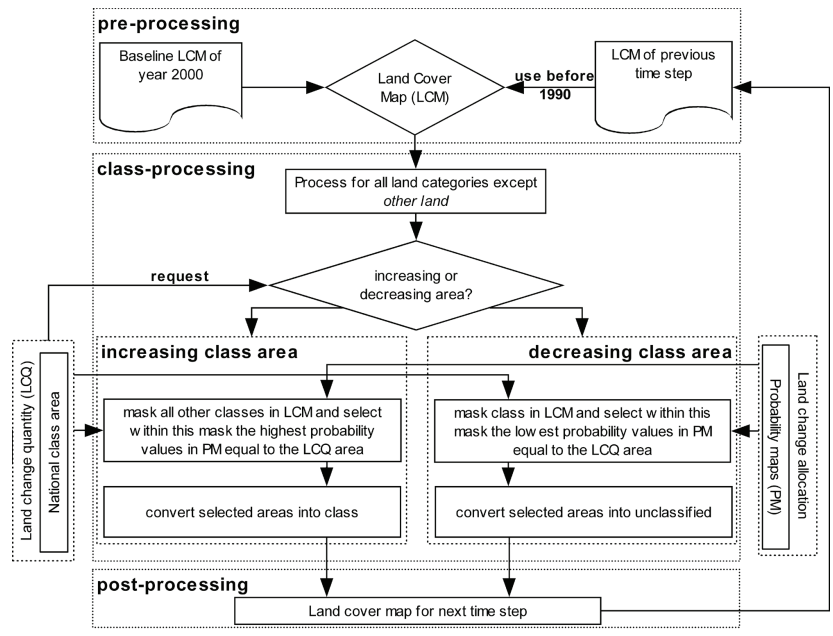

Fig. 2. Exemplary workflow of the model approach for one country.

\subsection{Model structure and processing}

The approach processes the data in decadal time steps for each country separately. Each time step can be separated into a pre-processing phase (Fig. 2, upper box), a class-processing phase (Fig. 2, middle box) and post-processing phase (Fig. 2, lower box).

In the pre-processing phase it is decided which land cover map (LCM) has to be chosen. This is dependent on the time step that needs to be processed. If these time steps are 2010 or 1990, the baseline map of the year 2000 is used, otherwise the LCM of the previous time step is used.

For land allocation in the class-processing phase, the model follows a process hierarchy. The land categories are ranked by its socio-economic value, so that settlements are calculated first, croplands second, forest third, and grasslands last. Forest was ranked third because its area has been almost constantly increasing since 1950, according to land change quantity data (LCQ). This implies an increasing aggregated area to be allocated. On the other hand, grassland was calculated last, since it was mainly decreasing according to the LCQ data, implying a lower aggregated area to be allocated for that land. Furthermore, grassland contains pastures and natural grasslands (peatlands, highlands, etc.), so that the socio-economic value was assumed to be lower than for the other land categories.

The approach treats the other land class, which mainly consists of water, glaciers, bare soils and sandy areas (like beaches, desserts and dunes) as static, and therefore it was masked from the data set. Since other land areas are small, influences from climate, tides, and the meandering of rivers were considered to be low at this spatial resolution.

If a class is selected for processing the next time step, the model requests information from the LCQ database on increase or decrease of the class area (Fig. 2, left vertical box). Every class that increases its area from one time step 
to another uses the probability map of its own class for all areas where this class can potentially grow (including unclassified areas). The selected areas are then converted into the according class (Fig. 2, middle box). Should the class decrease, the model masks the relevant class instead of all other classes, and picks the lowest values in the appropriate Probability Map (PM) equal to the LCQ area for that class. The area is then converted into unclassified area, which can be incorporated into other increasing classes later on as part of their increase mask (Fig. 2, middle box). Since the sum of all increasing and decreasing classes is zero at the end of one time step, all unclassified areas are assigned to a class. All new class areas are merged (including other land) to a new time step in the post-processing phase if all classes have been processed (Fig. 2 lower box).

\subsection{Comparative assessment and validation}

In order to check the performance, the approach was compared with other land change reconstructions available for this scale. Four relevant global models were chosen: Goldewijk, Ramankutty, Pongratz and Hurtt. Their spatial, temporal and thematic features are shown in Table 1. Our approach comprises pastures and natural grasslands as a result of the harmonization process to the IPCC land category. That implied that the comparative assessment between these reconstructions and ours was only possible for cropland. On the one hand, the comparison was performed in a spatially explicit way to point out the differences of detail due to the resolution and to show similarities and discrepancies of regional hotspot patterns. On the other hand, a time-series was elaborated for four European regions (Northern Europe, Eastern Europe, Southern Europe and Western Europe) to show differences of the total class area per region among the investigated land reconstructions. Finally, to evaluate the performances and accuracies of all approaches with ours, the results were cross-validated with already classified high-resolution aerial photographs for the years 1950 and 1990 in 73 different locations (validation site ca. $30 \mathrm{~km}$ by $30 \mathrm{~km}$ ) distributed across Europe (Fig. 3). The study sites cover 17 different countries of five bio-geographical zones (Boreal, Atlantic, Continental, Alpine and Mediterranean) with an area of $59.297 \mathrm{~km}^{2}$, which is about $1.5 \%$ of the total surface area of Europe. This validation material was obtained from Gerard et al. (2010).

It was possible to use the same class aggregation scheme for the five IPCC classes (LCCS) and for the CORINE product, since they use the same nomenclature and definitions. For this study the results were compared for 1950 and for 1990. Unfortunately, the data for 2000 were not available for all validation sites.

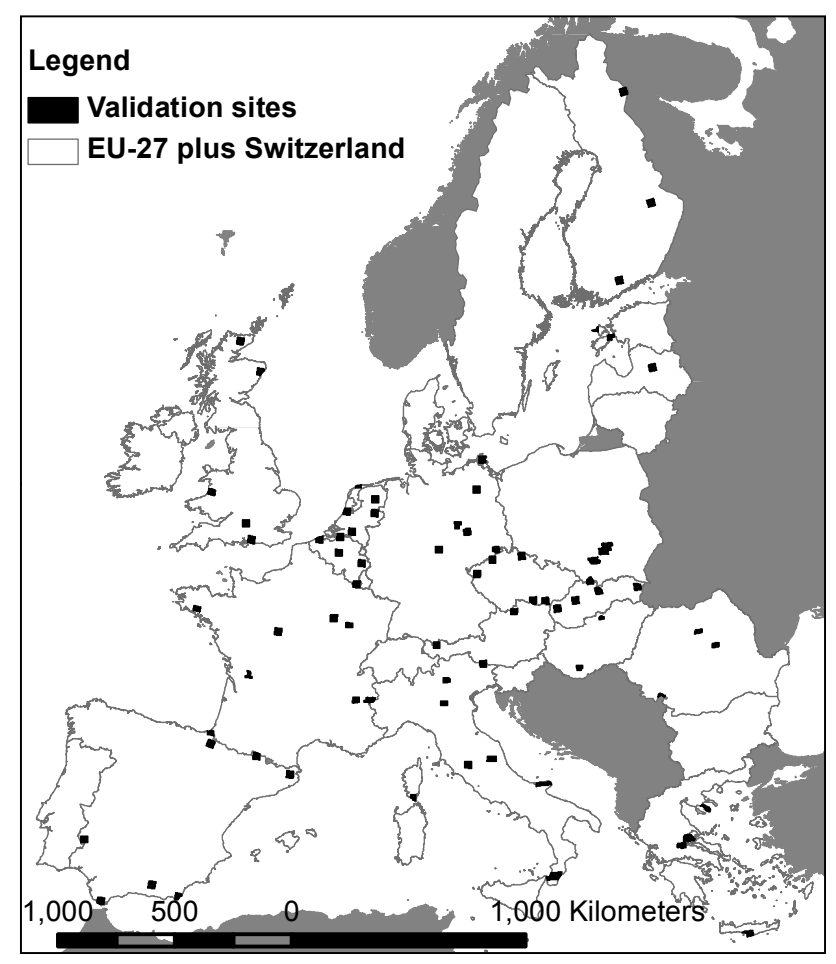

Fig. 3. Overview of validation sites for this study.

\section{Results}

\subsection{Land use reconstructions}

The result was analysed for the period 1950-2010 (Fig. 4) and is separately displayed for the years 2010, 1990, 1970 and 1950. The five IPCC classes and a water mask (sub class of other land) are shown for all EU-27 states plus Switzerland.

For the whole period it can be observed that forest has increased the most since 1950 by $314177 \mathrm{~km}^{2}(+25.35 \%$ or $0.42 \%$ per year) as well as settlements with $35818 \mathrm{~km}^{2}$ $(+24.54 \%$ or $0.41 \%$ per year). On the other hand, cropland decreased by $278922 \mathrm{~km}^{2}(-18.73 \%$ or $0.31 \%$ per year $)$ and grassland (pastures and natural grassland) by $73283 \mathrm{~km}^{2}$ $(-5.63 \%$ or $0.09 \%$ per year).

The growing population of Europe within the last $60 \mathrm{yr}$ $(+122 \mathrm{M})$ has led to the development of settlement agglomerations across the entire study area, especially in the population belt, known as the blue banana (Brunet, 1989).

Forests in Sweden increased their coverage by almost $20 \%$ within $60 \mathrm{yr}$ compared to 1950 , mainly occurring between the lake Vänarn and Stockholm. In Finland the same patterns occur, although more heterogeneously, for the coastal region reaching from Saint Petersburg in Russia to the upper Gulf of Bothnia. 


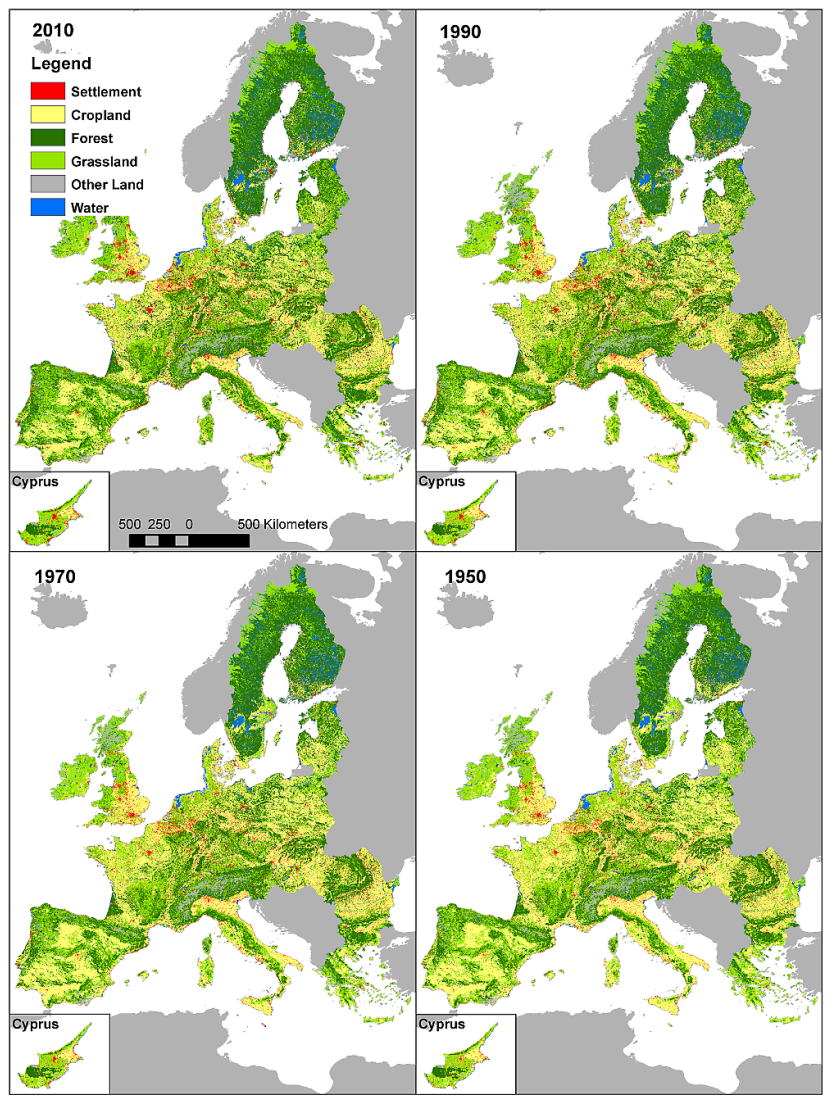

Fig. 4. Reconstruction results for four time steps: 2010, 1990, 1970 and 1950 and five classes (settlement, cropland, forest, grassland and other land; water mask is part of the other land class) for EU27 + Switzerland.

The Baltic States underwent a notable land transformation. The loss of cropland and the increase in forests and grassland can be determined as the main drivers for that region.

For the Mediterranean countries it can be concluded that the coastal areas of Italy, Spain and southern Portugal experienced a considerable drop of cropland by simultaneous conversions into mainly grasslands and to a minor extent into forests. Especially the regions of Alentejo in Portugal and Tuscany in Italy are affected by these changes.

The forest for France increased from $109540 \mathrm{~km}^{2}$ (1950) to $159540 \mathrm{~km}^{2}$ (2010) by $50000 \mathrm{~km}^{2}$, mainly occurring in the Provence and around Paris, which implies an increase of $45.64 \%$ within the last $60 \mathrm{yr}$. The same conversion type occurred also in Poland, more or less spread over the whole country, reaching a forest increase of $+35.14 \%$ between 1950 and 2010. In Romania, while forests stayed almost constant, the main driver was the drop in cropland in the Transylvanian and Moldavian regions, resulting in increasing grassland areas.

Accumulating the land changes between every single time step, a hotspot map can be generated for the whole period (Fig. 5). The hotspot map allowed focusing just on the mod-

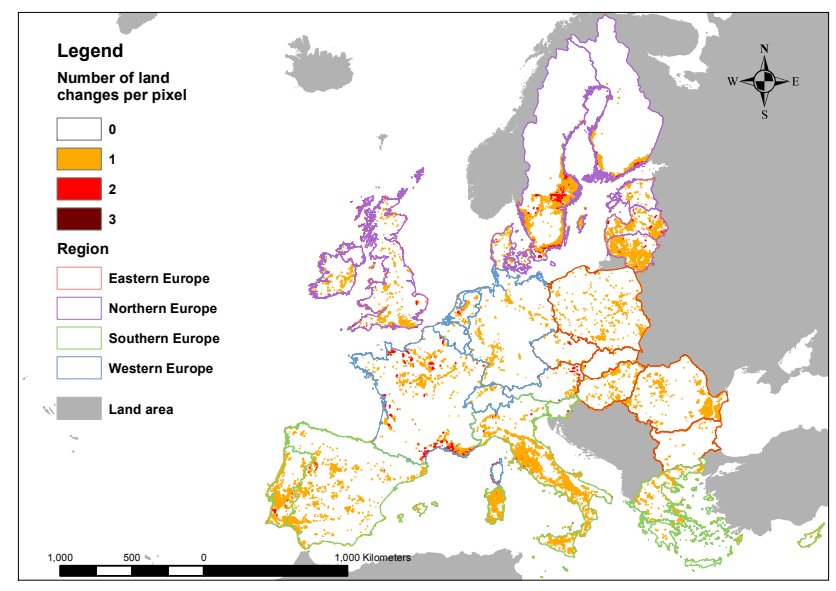

Fig. 5. Generalized prime hotspots of Europe for the period 19502010, showing the spatial distribution of (multiple) land changes.

elled land changes instead of on the coverage, in order to analyse the spatial hotspot patterns and agglomerations of multiple land changes per pixel. This way, hot spots are highlighted and clustered for visualization. Moreover, it shows areas of multiple land changes that mainly took place in France, Scandinavia, the Baltic States, Czech Republic, Austria, Italy and Portugal. This could be used to calculate the overall land changes for the entire study area with varying regional amounts of land changes. Therefore, the study area was separated into four major regions: Northern Europe, Eastern Europe, Southern Europe and Western Europe (see Fig. 5 and Table 2).

For the investigated period the area of affected land by land changes could be calculated as $601154 \mathrm{~km}^{2}$, which is $13.79 \%$ of the total area of all EU27 states plus Switzerland (Table 2). If the amount of all land changes is considered (including multiple land changes) an area of $674684 \mathrm{~km}^{2}$ has changed, which is $15.47 \%$ of the EU27 + Switzerland region. This implies that every year $0.26 \%$ of the entire $4.36 \mathrm{M} \mathrm{km}^{2}$ is converted, an area similar to Northern Ireland (Fig. 5). While the amount of changes of Northern and Eastern Europe follows the total average of land changes, Western Europe was roughly $2 \%$ below average. Contrary to that, Southern Europe was roughly $3.5 \%$ above average.

Figure 6 separates the relative amount of all land changes per region occurring between 1950 and 2010 into their main land conversion types. The two main land conversion types for these regions were either grassland to forest or cropland to grassland, incorporating together $63 \%$ (Eastern Europe) to almost $85 \%$ (Southern Europe) of land change areas per region. These conversion types were followed by cropland to forest, grassland to cropland and cropland to settlement. 


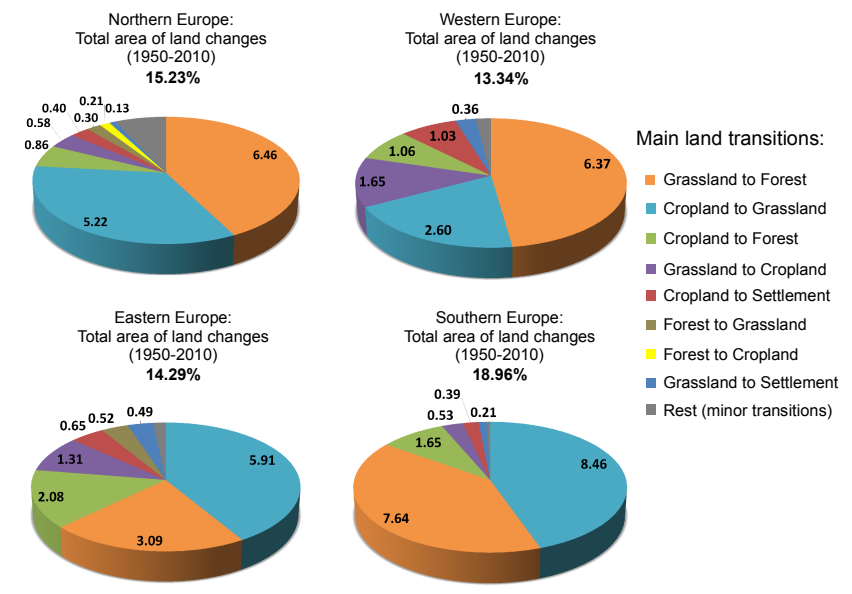

Fig. 6. Main land transitions and relative amount of land changes per region for 1950-2010.

\subsection{Comparative assessment and validation}

One objective of this study was to compare and evaluate our land reconstruction results with Goldewijk, Ramankutty, Pongratz and Hurtt (see Table 1). The spatial comparison is displayed in Fig. 7. Since the Hurtt product is based on the Goldewijk database and rescaled to 0.5 degrees, it was left out for the spatial pattern analysis. Due to the fact that our approach covers grasslands (incl. pastures and natural grassland) instead of pastures, the direct comparison with the global models was only possible for croplands. Although the units of each model result are different, the quantities and allocations can be compared quite well.

In a direct comparison with the other models it is notable to which extent our approach is increasing the spatial resolution and variability. A lot more details in the allocation of cropland can be seen, and distinguished for smaller regions, although the Goldewijk model reaches a decent level of detail for a global model on a European level.

It can be observed that in general all models show a wide range of similar patterns (e.g. Po Valley in Italy, Danube Delta in Romania and the Hungarian cropland area along the Danube), but also a large number of differences. These are most dominant in south-east England (Goldewijk), south-east Italy (Ramankutty), Poland (Pongratz), north-west France (Goldewijk), Scandinavia (Goldewijk, Pongratz). The occurrence of some hotspots for cropland quantities as well as their absence in some models is strange. For example, one of the most intensive cropland areas of the Pongratz model is Poland, while hotspot regions of other models in Spain are just average in this model. Another missing overlap can be observed for southern Sweden and Finland. While our approach and Ramankutty show a significant agglomeration of croplands for 1950, this pattern is almost missing in the Goldewijk and the Pongratz model.

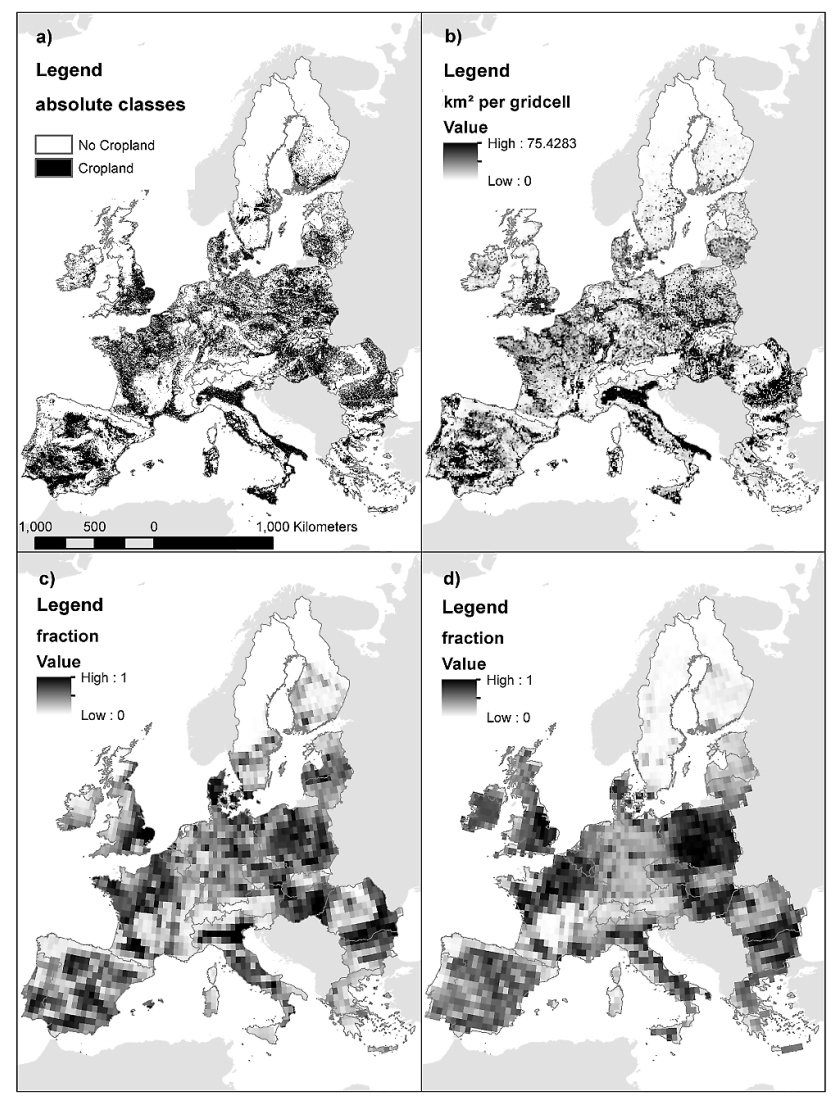

Fig. 7. Model comparison for cropland in the year 1950 for EU27 + CH: HILDA (1 km by $1 \mathrm{~km}$, absolute classes) (a), Goldewijk (0.05 deg, $\mathrm{km}^{2}$ per grid cell) (b), Ramankutty (0.5 deg, fractions) (c), Pongratz (0.5 deg, fractions) (d).

In addition to a model comparison on spatial quantity patterns and land category allocations for cropland, the area fractions of cropland over time were compared for the EU27 + Switzerland area and the abovementioned regions (see Fig. 5). The result for the cropland class in EU27 + Switzerland can be seen in Figure 8. The figures per European region are shown in Appendix C. In general, all models were showing the same land conversion quantity (yearly change rates), but the absolute fractions of land coverage by cropland differed significantly. While for EU27 + Switzerland this difference was only $1 \%$ in 1990 (30\%-31\%) for all models except Pongratz (ca. 37\%), it reached a range from $31 \%$ (Hurtt) to $40 \%$ (Pongratz) for 1950. Our approach was the only one which processed the time step 2010. It is interesting to see that before 1960 all other models assume a trend change, while our land reconstruction continued with the same trend, which is likely caused by the fact that global models rely on FAOSTAT data since 1960 and before on linear model based estimates.

In order to evaluate the quality of the land cover reconstruction, a comparison with independent observation data at higher resolution was made as a means of validation. This 
Table 2. Land change amounts for four different European regions and EU27 + Switzerland for the period from 1950-2010.

\begin{tabular}{llll}
\hline Region & $\begin{array}{l}\text { Total area in } \\
1000 \mathrm{~km}^{2}\end{array}$ & $\begin{array}{l}\text { Total area affected by } \\
\text { land changes in } \\
1000 \mathrm{~km}^{2}(\mathrm{excl} \text {. multiple } \\
\text { land changes) }\end{array}$ & $\begin{array}{l}\text { Total land changes } \\
\text { in } 1000 \mathrm{~km}^{2} \\
\text { (incl. multiple } \\
\text { land changes) }\end{array}$ \\
\hline $\begin{array}{l}\text { Northern Europe } \\
\text { (IE, UK, DK, SE, FI, EE, LT, LV) }\end{array}$ & $1320(30.26 \%)$ & $173(13.05 \%)$ & $201(15.23 \%)$ \\
$\begin{array}{l}\text { Eastern Europe } \\
\text { (PL, CZ, SK, HU, RO, BG) }\end{array}$ & $882(20.24 \%)$ & $117(13.24 \%)$ & $126(14.29 \%)$ \\
$\begin{array}{l}\text { Southern Europe } \\
\text { (CY, GR, IT, SI, MT, ES, PT) }\end{array}$ & $1058(24.27 \%)$ & $186(17.50 \%)$ & $201(18.96 \%)$ \\
$\begin{array}{l}\text { Western Europe } \\
\text { (FR, BE, NL, LU, DE, CH, AT) }\end{array}$ & $1100(25.22 \%)$ & $123(11.19 \%)$ & $147(13.35 \%)$ \\
\hline Total & $4360(100 \%)$ & $601(13.79 \%)$ & $675(15.47 \%)$ \\
\hline
\end{tabular}

was done with the historic aerial photographs obtained by Gerard et al. (2010). All 73 samples of the years 1950 and 1990 were used to validate the outcomes of the land reconstruction approach.

Four examples of representative test sites are shown in Fig. 9. The left column shows the results of our land reconstruction, the right column the sample sites of reference data. The four examples display the year 1950 and 1990 for each data source.

In general, by comparing the two data sets, it could be recognized that the historic land reconstruction could mainly cover the main land change trends of the Gerard et al. (2010) data set (e.g. increasing areas of settlements, reforestation, cropland decrease, etc.). The sample sites of Amsterdam and Haarlem (NL) and Grenobles (FR) indicate that during the backcasting to 1950 , our approach was able to reduce the amount and to keep the shape of settlement areas as determined by reference data. However, in some parts differences remain. While the historic land change approach considered the south-east to be more stable, the southern region already existed in the 1950s. The urbanization of the suburbs was well captured, although the area of Haarlem (middle western part) was a bit underestimated. The example of the Carpathian Mountains in Romania demonstrates that the approach was also able to cover land changes like clear-cuts in forest areas, although the patches were difficult to capture with a $1 \mathrm{~km}$ resolution. The fourth sample site (Vecpiebalga, LV) was affected by afforestation in the southern section. The historic land change model was capable to reconstruct this land conversion. However, it found the land change area in the middle of the southern section, whereas it was in the left southern section according to the reference data.

Besides the visual comparison in Fig. 9, the two products were cross-validated for each of the 73 validation sites for the time steps 1990 and 1950 by comparing the area coverage per class for each validation site. As indicator we chose the relative root mean square error of prediction (RRMSEP) which was calculated as follows:

$$
\operatorname{RRMSEP}=\sqrt{\frac{\sum_{i=0}^{n}\left(r_{i}-p_{i}\right)^{2}}{n}} / \emptyset_{r},
$$

where:

- $r_{i}=$ reference class area;

- $p_{i}=$ prediction class area;

- $n=$ number of sites; and

$-\emptyset_{r}=$ average of reference class area.

For 1990 we calculated an RRMSEP of 0.21 for settlement, of 0.41 for cropland, of 0.37 for forest, of 0.72 for grassland and of 0.53 for other land. For the year 1950 the RRMSEP was 0.50 for settlement, 0.50 for cropland, 0.46 for forest, 0.70 for grassland and 0.57 for other land. The values for 1990 indicate that between our approach and the reference data, an average area disagreement ranging from $21 \%$ to $72 \%$ existed. These location errors are likely induced by the differences between our baseline map and our reference data. For instance it was noticed that in the most northern validation site in Finland, the reference data set derived almost a complete coverage of forest $(94 \%)$, whereas our baseline map yielded a grassland coverage of $94 \%$. This appeared also for some other sites.

The comparison of RRMSEP between 1990 and 1950 revealed that our approach induces more area errors, the further it models back in time. Whereas all reference samples sites together comprised an average area change of $4 \%$ between 1950 and 1990 for the classes studied, our approach derived an overall area of about $8 \%$ affected by land changes for these sample sites.

It should, however, be noted that the small area changes in the reference data are largely the result of persistence in land 


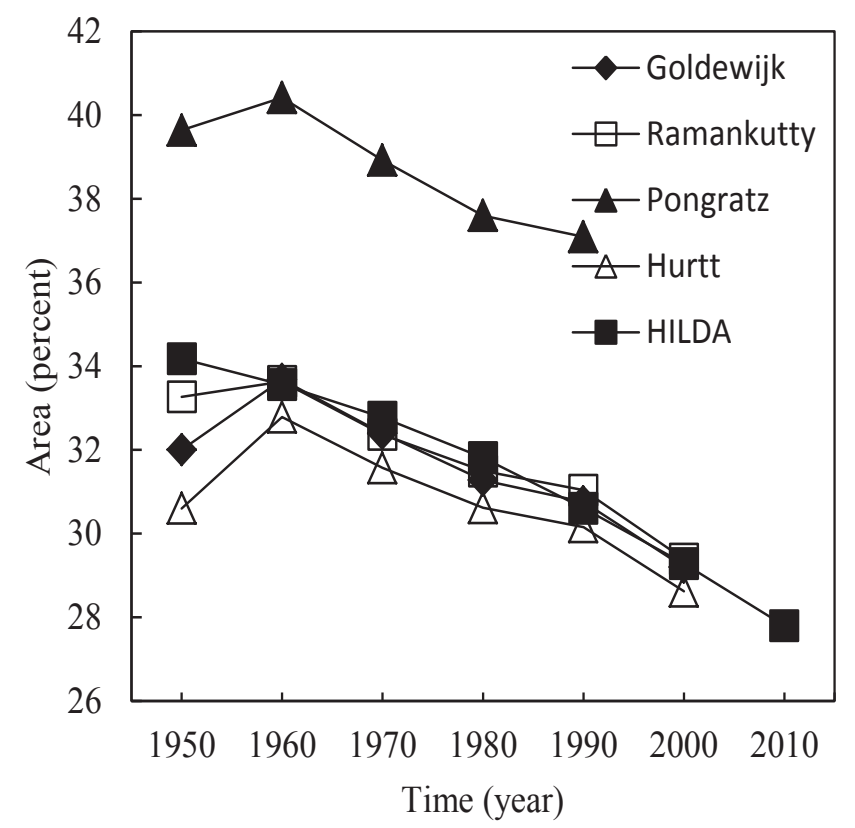

Fig. 8. Area fractions for cropland, compared in decadal time steps from 1950 to 2010 for EU27 + Switzerland.

cover: the overall distribution of land cover across the test sites remained the same across the two years, especially as many of the reference sites were located in relatively stable rural areas. This persistence often led to high correspondence levels in land cover model validations (Pontius et al., 2008).

In general the validation with reference data revealed that our approach could capture the main land change hot spots and its conversion types correctly in many cases. Both the reference data and our approach showed an increase in urban and forest areas (mainly due to cropland and grassland losses) and a decrease in cropland and grassland areas (due to afforestation and urbanization) between 1950 and 1990 . However, detailed comparison of the maps revealed larger deviations in predicting the exact location of change. The area affected by change and its change rate were smaller than those of the modelled land cover for EU-27. This was because of the sampling size and a bias towards areas containing nature reserves. Therefore, it was not possible to produce statistically reliable estimates of land cover change for larger areas (Gerard et al., 2010).

Nevertheless, compared with the existing global land use reconstructions, the validation showed that the presented historic land reconstruction is capable of describing land changes at a higher spatial and thematic resolution leading to a realistic representation of the landscape composition and pattern, which is of high importance for reliable assessments based on such data (Verburg et al., 2012). While our approach could provide complete thematic information on land changes within validation sites, global models could only provide information on some classes with a spatial resolution
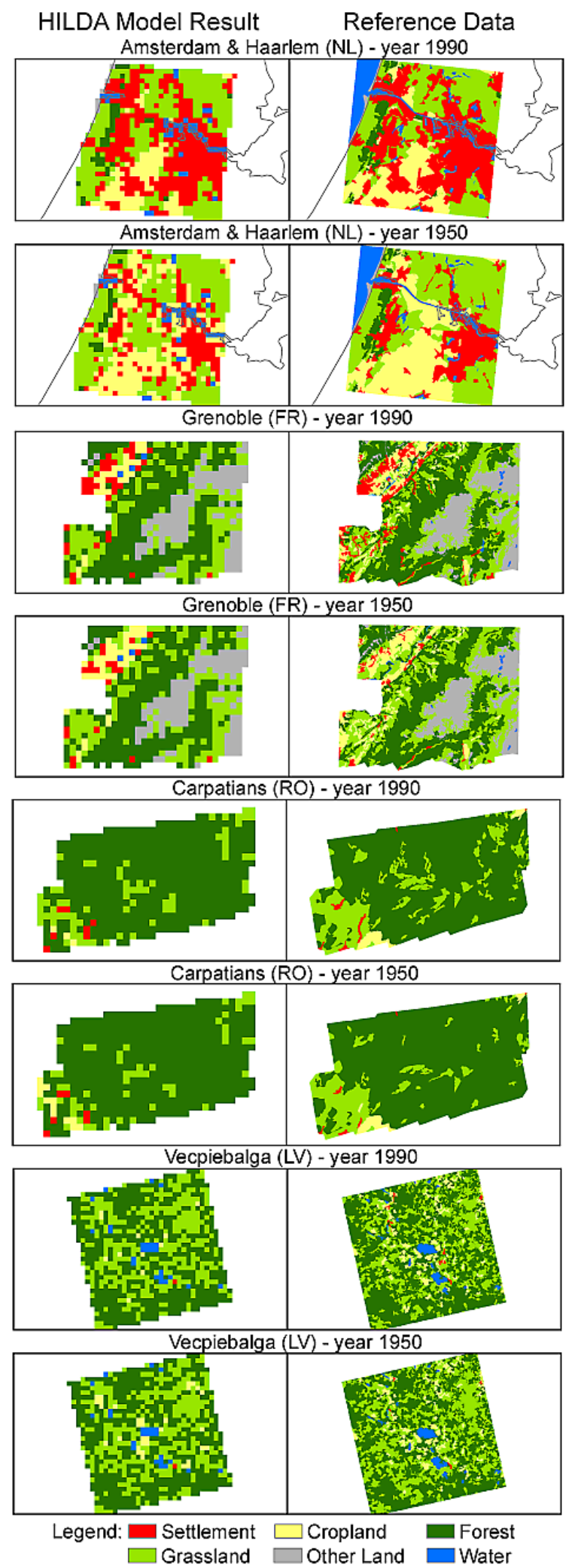

Fig. 9. Model validation (left) for four regional case studies with reference test sites (right), each for the years 1950 and 1990. 
that is for some of the data as coarse as a whole reference test site.

\section{Discussion}

\subsection{Land reconstruction}

Analysing the reconstructed land conversions of the investigated period for Europe, the main conversion types were grassland to forest, cropland to grassland, cropland to forest, grassland to cropland, and cropland to settlement (Fig. 6). Together all changes led to $674684 \mathrm{~km}^{2}$ (15.47\%) of changed land within the last $60 \mathrm{yr}$, an area similar to France (Table 2). Although we cannot determine the proximate cause and underlying driving factors of these land changes based on the analysis in this paper, some of the locations of major land changes can be related to major political decisions. Examples include the timber shortage after the Second World War, the urbanization due to the increased population, the controlled economy in countries belonging to the Russian Federation until 1990, the Common Agricultural Policy (CAP) and its accompanying afforestation actions.

\subsubsection{The post-war urbanization of Europe}

The increase of settlement area of about $35818 \mathrm{~km}^{2}$ $(+24.54 \%$ of new urban area) throughout Europe since 1950 is a clearly visible effect in the results. During the investigated period the population increased by $122 \mathrm{M}$ humans, who migrated from rural areas into cities. Particularly the western capitalistic countries (Germany, England, France, Belgium, Netherlands, etc.) experienced quite an economic boom after the Second World War, resulting in such urbanization (Crafts and Toniolo, 2008). These land changes occur mostly where large settlement areas can already be found, especially world and global cities and their agglomerations. They cover the highest density of commerce, money, industries and related human capital (Fig. 10). City clusters along the Blue Banana were mainly affected as well as cities like Madrid, Berlin and Paris.

\subsubsection{The European timber shortage after World War II and European afforestation actions}

The total area of forest increased by $314177 \mathrm{~km}^{2}(+25.35 \%$ of new forest land) (Fig. 10) since 1950. This land conversion could be seen in almost every country, with the main increase in Western and Northern Europe (Fig. 6). After the two World Wars and rigorous resource exploitation due to former land use, the European forests were in a critical situation. The timber shortage was induced by the economic demand for wood products and led to several national afforestation actions (FAO, 1947, 1948). One hotspot is southern Scandinavia. Although Sweden and Finland always exported timber for the last few centuries, they released land reforms at

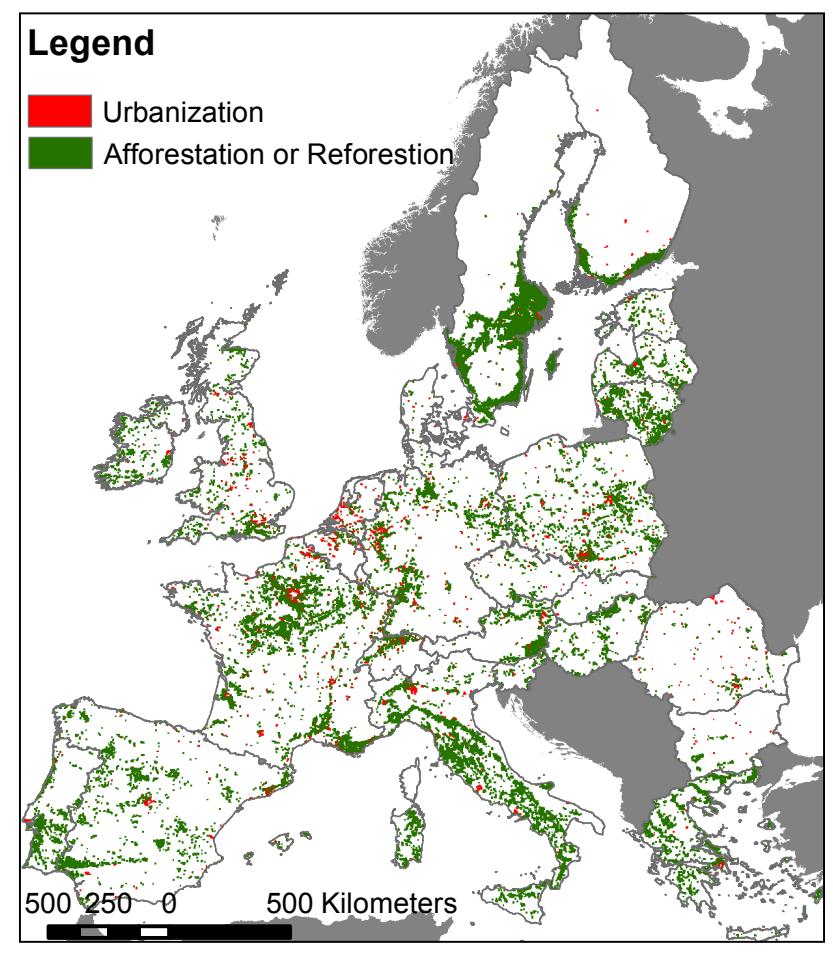

Fig. 10. Prime areas of major urbanization and afforestation/reforestation hotspots for the period 1950-2010.

the beginning of the last century, which regulated the management of their forests (Meissner, 1956). Before these land reforms, in the 19th and beginning of the 20th century, primary forests were cut by subsistence farmers using a mixed form of management between forest, cropland and grassland. Later on, large scale forest enterprises managed the land, focusing only on wood supplies (Royal Swedish Academy of Agriculture and Forestry (KSLA), 2009). Croplands were abandoned, resulting in fallow land, and afforested by the companies with seedlings, resulting decades after the last land reform in new managed forest areas. The results show this transition, taking the temporal gap of cropland and forest demand into account (Fig. 5).

After the collapse of the Austrian-Hungarian Empire in 1918, and the loss of the Upper-Hungarian area to Czechoslovakia and large parts of Transylvania to Romania in 1938/1940, Hungary lost the main forestry areas of its previous realm (ca. $84 \%$ ) (Dauner, 1998). This loss led to subsequent afforestation actions of the remaining area, especially in the Plain, resulting in a forest area increase from ca. $12 \%$ in 1938 (Dauner, 1998) to ca. $22 \%$ in 2010.

During the same period the forest area in the Baltic States increased as well. The area increase after World War II and during the 60s took place when natural afforestation recaptured the land and the abandoned agricultural land was afforested (Ozols, 1995). In the 90s this trend proceeded after the Fall of the Iron Curtain (see Sect. 4.1.4) and the 
introduction of the CAP (Common Agricultural Policy) (see Sect. 4.1.3).

In the 1990s the EEC Regulation No 2080/2092 included afforestation as forestry measure in the European Law to further decrease the deficit of European timber production. Accompanying the CAP, less productive agricultural land should be converted into forest areas to steer and optimize the production of natural goods and to support the preservation of the environment (EEC, 1992, 2005). From 2000 to 2006, afforestation actions were stipulated by the Regulation (EC) No 1257/1999 (EEC, 1999, 2005).

\subsubsection{Cropland changes before and after the introduction of the Common Agricultural Policy}

The CAP of the European Union came into effect in 1990. By guaranteeing farmers subsidies and a standard of living, this policy forced the reorganization of agricultural land (cropland and pastures) to be more competitive for global markets (Pinto-Correia and Vos, 2004). Several regions (e.g. the province Alentejo in Portugal) became unattractive due to their higher management effort and lower accessibility and were converted into other land forms within just a few decades (Pinto-Correia and Vos, 2004).

In the whole of Europe an area of $144733 \mathrm{~km}^{2}$ of cropland was converted into grassland and forests since the start of the CAP (1990-2010) (Fig. 11). This is an increase by $150 \%$ in comparison to the same period before 1990 (19701990) $\left(95990 \mathrm{~km}^{2}\right)$. The former socialistic states (incl. Baltic countries) and Mediterranean countries like Spain, Portugal and Italy can be clearly seen as major hotspots. In Southern Europe the increase even exceeded 200\%. From 1970 to 1990 the converted cropland area was $30638 \mathrm{~km}^{2}$, as of 1990 it was $61404 \mathrm{~km}^{2}$. Additionally, Southern Europe experienced growth in land changes, which were $4 \%$ above the European average (Fig. 6). Eighty-five percent $(85 \%)$ of the land changes that occurred in this region were due to land conversions from cropland to grassland or grassland to forest, although it cannot be distinguished whether these land changes are cropland abandonment, conversion into pastures or driven by the reforestation actions of the EU.

Before the introduction of the CAP, main change patterns of cropland could be seen for example in Hungary as a result of the afforestation actions of the late 30s (see Sect. 4.1.2) due to forest area losses after World War I. Similar patterns occurred in Scandinavia and areas of France, Spain and Italy, where several land reforms led to these changes (see Sect. 4.1.2).

\subsubsection{The fall of the Iron Curtain}

The same conversion effects resulting from the CAP can be seen for the Baltic States (Fig. 11) mainly since 1990, but under a different political situation. Lithuania, Latvia and Estonia were part of the Soviet Union before 1990, and car-

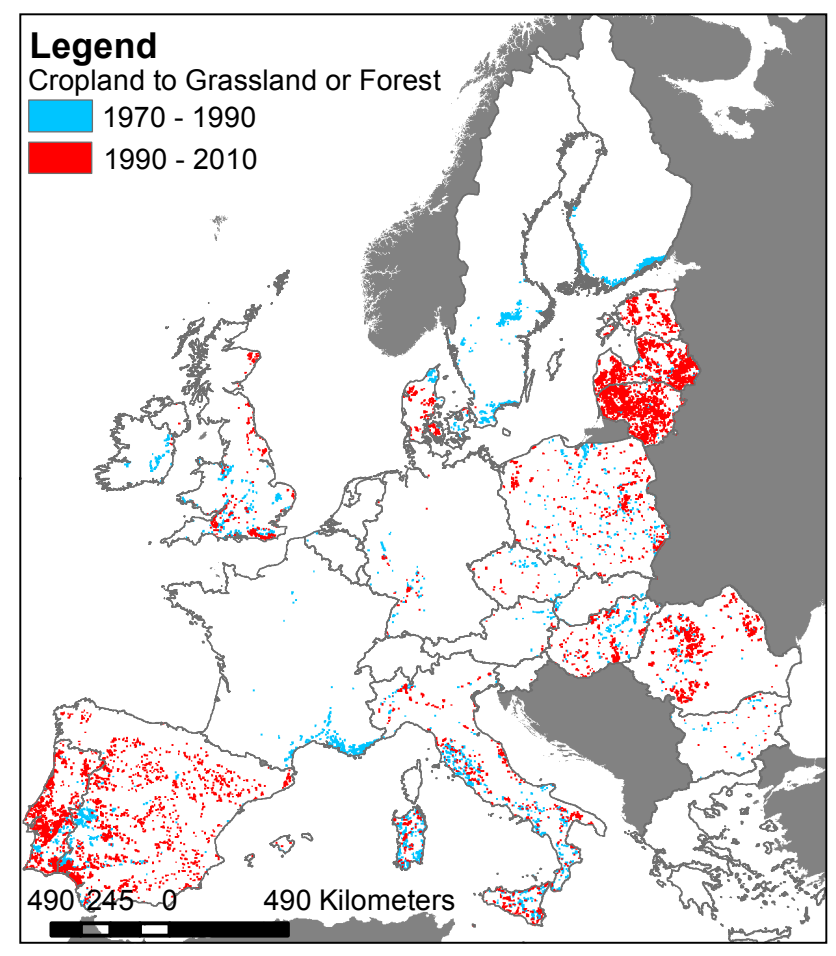

Fig. 11. Prime areas with loss of cropland. Cropland to grassland or forest is displayed separately for two 20-yr groups, before and after the introduction of the Common Agricultural Policy in 1990.

ried out a planned economy, resulting in large areas of cropland. After the fall of the Iron Curtain, the agricultural system was not competitive on the international market, due to low productivity, high-pollution machinery and high energy consumption, so that the value of wood production became more important, resulting in afforestation areas and fallow cropland (Mander and Kuuba, 2004; Prishchepov et al., 2012).

Before 1990 Romania has also been led by a planned economy of the Soviet Union. The main focus was on cropland due to the Mediterranean climate, but the international markets in the 1990s entailed that the supply and the production methods were not competitive enough to survive, due to the same reasons for almost every Eastern European country: low productivity, old and high-pollution machinery, and high energy consumption. Large areas in the Transylvanian and Moldavian province have been turned into fallow land (Kuemmerle et al., 2009; Mueller et al., 2009).

The main land conversion types of Eastern Europe were cropland to grassland, grassland to forest and cropland to forest (Fig. 6). Together they caused $78 \%$ of all land changes in that region as of 1950. Most of these changes occurred after the fall of the Iron Curtain. The effects, before and after this event, can be seen for two of these conversion types in Fig. 11. 


\subsection{Comparative assessment and validation}

The comparison with global models revealed differences in the spatial allocation of land cover. Figure 7 illustrates this for cropland. Differences could be attributed to the various distribution methods of each model, considering different assumptions for the allocation of land cover and its changes. However, the absolute differences (Fig. 8) could also originate from different baseline data sets, from processing in a non-equal area projection (all global model results are given in WGS84), a different change data basis, methods for gap filling of land change data, cross country allocation procedures and wrong assumptions for areas with poor data.

The validation with the reference data revealed that our results could capture most of the overall patterns of land change, although deviations with the observed data remain. The higher inaccuracies in the results for the grassland class can also be attributed to the known problems of CORINE to differentiate between cropland and grassland (Maucha and Buettner, 2005; EEA, 2006). Since our study also combines pastures and natural grassland areas, it assumes the same dynamics for both land cover types, which is in reality not the case.

\subsection{Methods}

Due to the combination of new and more suitable data sets for Europe as well as better and more detailed modelling techniques, the results of our approach can be used to considerably improve GHG and climate assessments compared to existing methods. By the use of the presented method and available data for Europe, new synergies have arisen, like a high spatial resolution, flexibility in processing and the consideration of a full land change balance with its land conversion types.

In comparison to other land reconstructions, we have only considered a relatively short time period in which we could base the national land areas on available census data and other sources. Global historic models like HYDE (Ellis et al., 2012; Klein Goldewijk et al., 2010, 2011) have reconstructed land change over much longer historic periods and are therefore relying more on assumptions about management practices and class relations to process land categories over time (e.g. population/cropland ratios or livestock/pasture ratios). This is because land data are rare or often not available for their covered areas and periods (centuries to millennia) for all time steps. The higher spatial-thematic detail of our study responds to the demands by the GHG community (Ciais et al., 2011; Schulze et al., 2010) providing base maps for GHG inventories and further information about the influence of land change on emissions. As a baseline year we used the year 2000 , where data availability, quality and overlap along the products were best. However, the approach is flexible in using different base years if new data become available.
In many cases spatially explicit land cover time series (e.g. such as Landsat from the early 70s) could support and improve ongoing land reconstructions. Unfortunately, there is still no available land cover product such as CORINE for the 70s and 80s, which can be used for land reconstructions.

Although European level simulations of future land change were available (Rounsevell et al., 2006; Verburg et al., 2010) the underlying models were not directly applicable to provide backcasting. Many land change models used for simulation of future scenarios account for path-dependency in the land system evolvement and are therefore not suited for reconstructing land use history in a backward mode or for dealing with limitations in historic data availability. The land allocation approach used in this paper is much simpler and not path-dependent and therefore more suited for the specific purpose of this paper.

The assumption of constant probability maps for the whole modelling period might lead to limitations in the allocation approach. They are econometrically fitted based on the current time relations between drivers and land use. Although many factors are considered to be quite stable in time (e.g. climate-, terrain- and soil factors), this may have been different in the past for some of them (e.g. for accessibility or population density). However, the estimation of the probability maps has been done at national scale (with countryspecific factors) and was widely used and tested in multiple land use modelling efforts in a foresight mode (Verburg and Overmars, 2009; Verburg et al., 2008, 2010)

Furthermore, the allocation factors considered in the probability maps have been based on factors often used and mentioned in other historic case studies of land change processes, such as Klein Goldewijk et al. (2010, 2011) (population density, soil suitability, accessibility, terrain factors, climate factors etc.), Kaplan et al. (2009) (population, soil and climate factors), Pongratz et al. (2008) (population before 1700, and from 1700 onwards factors of Klein Goldewijk et al. (2010, 2011) were used), Olofsson and Hickler (2008) (used factors from Klein Goldewijk et al., 2010, 2011).

The chosen class hierarchy was most suitable for adapting the real land developments. However, it has implications on the final result that have to be considered. The hierarchy approach requires that all territorial claims of a higher ranked class are satisfied first, which is in reality not always valid. It is rather the case that each class has dominant and less dominant conversion types (e.g. increasing settlement area is incorporating $60 \%$ of cropland, $30 \%$ of grassland and $10 \%$ of forest areas). On the other hand, this consideration would require knowledge about gross land changes (e.g. provided by spatially explicit information or statistics which consider such a conversion matrix), instead of net land changes (e.g. provided by statistics on an administrative basis). However, a full consideration of the gross/net changes was not possible for our product, as this would require the comparison of consistent, spatially explicit maps or statistics covering the whole period, which account for 
gross changes (often these statistics were obtained from remote sensing products). The only product where a comparison would have made sense, was the CORINE data set with the time steps 1990, 2000 and 2006. Unfortunately, CORINE does not cover the whole period. The UMD data set uses data of roughly a $20 \mathrm{yr}$ period, which makes it difficult to account for changes when comparing with other data sets. The GlobCORINE data set comprises only a few years (2005 and 2009) and the period is covered as well by the CORINE data sets. The statistics we used only accounted for the total area of a land cover class. So, we were missing the information of the change matrix. Additionally, all these maps are affected by misclassification, which increases the uncertainty of the gross change estimation. Most often these classification errors occur for rapidly changing classes, such as cropland and grassland.

Nonetheless, we calculated the net/gross change difference for CORINE 1990 and 2000 for the entire study area to provide an order of magnitude for this difference. The land change intensity of gross land changes exceeded the net changes by roughly $160 \%$ for settlements, cropland and forest. For grasslands it even exceeded the net by $450 \%$. This underestimation by our approach is similar to the difference between UNFCCC reports and our estimates (see Sect. 4.4). However, the order of magnitude of the CORINE products varies very strongly if we consider another period, for example from 2000 to 2006. The land change intensity of gross changes was higher than for net changes, namely $170 \%$ for settlements, $1500 \%$ for croplands, $250 \%$ for forests and $300 \%$ for grasslands.

\subsection{Implications for GHG and climate models}

Besides the technical improvements on spatial resolution, which enables the study of more fine-scale variability in land changes than before, the results include new relevant land categories for GHG assessments, such as the settlement class and other land class (including inland water). Since all land categories in the presented approach thematically cover $100 \%$ of the land area together, it enables GHG models to take a full land change balance into account. This again affects the GHG balance. The importance of historic land changes and their effect on soil organic carbon (SOC) was pointed out by Poeplau et al. (2011). The associated uncertainties of SOC estimation on the GHG balance without sufficient land change information was addressed by Ciais et al. (2011). Furthermore, our approach allows relating land changes to their underlying proximity causes on an improved level of detail. This is an important advancement for GHG and climate research, since it supports the study on the effects of human activity on our climate.

However, this land change reconstruction processes net land change information, instead of gross change information due to the input data. Therefore, the change rate will be underestimated, since the dynamic of changes within admin- istrative boundaries is not well captured. Schulze et al. (2010) quantified the spatially inexplicit UNFCCC gross change rate per year to be $17800 \mathrm{~km}^{2}$ for EU25, whereas our results have a spatially determined yearly net change rate of $11336 \mathrm{~km}^{2}$ for EU27 and Switzerland.

Not only compared with other historic land reconstructions, but also with related novel satellite products and modern GHG reporting mechanisms, our approach has important added values for GHG studies, such as:

1. This approach and data set covers a longer period than modern reporting mechanisms for greenhouse gas emissions, which is important for legacy effects (e.g. soil carbon) and understanding of GHG processes.

2. Related remote sensing products cannot cover this time span.

3. None of the previous reconstruction products considered the most important land use classes (cropland, grasslands and forests) in one product and at an appropriate spatial resolution, in order to observe these land conversion types.

4. This approach combines and harmonizes multiple reporting mechanism in one product and often adds a spatial component.

5. Since gross changes cannot be directly derived from one product for the whole period, they have to be estimated by additional information. This difference with net changes should be applied on already existing model structures. Our approach can be used for that in future studies.

\section{Conclusions}

The aim of this paper was to investigate whether the combination of different data sources, more detailed modelling techniques and the integration of land conversion types allow us to create accurate, high resolution historic land change data for Europe suited for the needs of GHG and climate assessments. By the use of multiple harmonized data sources and our modelling approach, we were able to process the historic land reconstruction on a $1 \mathrm{~km}$ spatial resolution for five IPCC land categories. Thereby, we focused on allocating existing harmonized land cover change data from census data rather than modelling these changes based on assumptions of change processes. The categories cover $100 \%$ of the land area, and take a full land change balance into account. This allows for the consideration of land conversion types.

The results indicate that almost $700.000 \mathrm{~km}^{2}(15.5 \%)$ of land cover in Europe has changed over the period 1950 to 2010, an area similar to France. In Southern Europe, the relative amount of change was almost $3.5 \%$ higher than this average. Based on the results, the specific types of conversion, 
hot-spots of change and their relation to political decisions and socio-economic transitions were studied. The analysis indicated that the main drivers of land change over the studied period were urbanization, the reforestation program due to the timber shortage after the Second World War, the fall of the Iron Curtain, the Common Agricultural Policy and accompanying afforestation actions of the EU.

The validation with historic aerial photographs from 1950 and 1990 for 73 sample sites across Europe revealed that our results could capture most of the overall patterns of land change, although deviations with the observed data remain. In comparison with other land reconstructions like Klein Goldewijk et al. (2010, 2011), Ramankutty and Foley (1999), Pongratz et al. (2008) and Hurtt et al. (2006) it could be shown that our approach performs in line with these land reconstructions. Furthermore, the new method takes account of the harmonization of different datasets by achieving a high spatial resolution and regional detail with a full coverage of different land categories. These characteristic allow the data to be used for supporting and improving ongoing GHG inventories and climate research.

\section{Supplementary material related to this article is

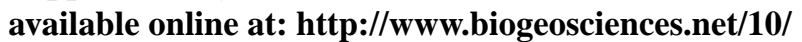 1543/2013/bg-10-1543-2013-supplement.zip.}

Acknowledgements. The authors would like to thank France Gerard and Sander Mucher for provision and assistance with the reference data. Financial support of the FP7 project GHG-Europe (Grant No. 244122) and the FP7 project VOLANTE (Grant No. 265104) is acknowledged. This paper contributes to the objectives of the Global Land Project (http://www.globallandproject.org). The HILDA data set can be obtained at http://www.grs.wur.nl/UK/Models/HILDA/.

Edited by: P. Stoy

\section{References}

Antrop, M.: The transformation of the Mediterranean landscapes: an experience of 25 years of observations, Landscape Urban Plan., 24, 3-13, 1993.

Bicik, I., Jelecek, L., and Stepanek, V.: Land-use changes and their social driving forces in Czechia in the 19th and 20th centuries, Land Use Policy, 18, 65-73, 2001.

Brovkin, V., Sitch, S., Von Bloh, W., Claussen, M., Bauer, E., and Cramer, W.: Role of land cover changes for atmospheric $\mathrm{CO}_{2}$ increase and climate change during the last 150 years, Glob. Change Biol., 10, 1253-1266, doi:10.1111/j.13652486.2004.00812.x, 2004.

Brunet, R.: Les villes europeénnes: Rapport pour la DATAR, Reclus, Montpellier, 1989.
Carni, A., Jarnjak, M., and Ostir-Sedej, K.: Past and present forest vegetation in NE Slovenia derived from old maps, Appl. Veg. Sci., 1, 253-258, doi:10.2307/1478955, 1998.

Ciais, P., Gervois, S., Vuichard, N., Piao, S. L., and Viovy, N.: Effects of land use change and management on the European cropland carbon balance, Glob. Change Biol., 17, 320-338, doi:10.1111/j.1365-2486.2010.02341.x, 2011.

Crafts, N. and Toniolo, G.: European Economic Growth, 19502005: An Overview, (6863), 1-60, available at: http://wrap. warwick.ac.uk/1671/1/WRAP_Crafts_CEPR-DP6863[1].pdf, 2008.

Dauner, M.: Information on forest management. A summary of annual report, Erdèszeti Lapok, CXXXIII(1), 1-3, 1998.

DiGrigorio, A. and Jansen, L.: Land-cover classification system (LCCS): classification concepts and user manual, FAO/UNEP/Cooperazione italiana, Rome, 2000.

Ellis, E. C., Antill, E. C., and Kreft, H.: All is not loss: plant biodiversity in the anthropocene, PloS one, 7, 1-9, doi:10.1371/journal.pone.0030535, 2012.

European Commision: EUROSTAT, available at: http://epp. eurostat.ec.europa.eu/portal/page/portal/eurostat/home/, 2012.

European Economic Community (EEC): Council Regulation (EEC) No 2080/92, Official Journal of the European Communities, 215, 96-99, available at: http://eur-law.eu/EN/ Council-Regulation-EEC-2080-92-30-June-1992,242179,d, 1992.

European Economic Community (EEC): Council Regulation (EC) No 1257/1999, Official Journal of the European Communities, 160, 80-102, 1999.

European Economic Community (EEC): Special Report No 9/2004 on Forestry Measures within Rural Development Policy, together with the Commisssion's replies, Official Journal of the European Communities, 67, 1-28, available at: http://scholar.google.com/scholar?hl=enandbtnG=Searchandq= intitle:COURT+OF+AUDITORS\#3 (last access: 25 June 2012), 2005.

European Environment Agency (EEA): The thematic accuracy of Corine land cover 2000, Copenhagen, 2006.

European Environment Agency (EEA): CORINE Land Cover Data, available at: http://www.eea.europa.eu/data-and-maps, 2012.

European Space Agency (ESA): GlobCorine, available at: http:// projects.eionet.europa.eu/leac/library/globcorine, 2011.

Food and Agriculture Organization of the United Nations (FAO): Timber shortage in Europe, Unasylva, 1, available at: http://www.fao.org/docrep/x5340e/x5340e06.htm\# timbershortageineurope, 1947.

Food and Agriculture Organization of the United Nations (FAO): Europe's timber problem, Unasylva, 2, available at: http://www. fao.org/docrep/x5346e/x5346e00.htm\#Contents, 1948.

Food and Agriculture Organization of the United Nations (FAO): FAOSTAT, available at: http://faostat.fao.org/default.aspx ?lang= en, 2012a.

Food and Agriculture Organization of the United Nations (FAO): Global Forest Resources Assessments (FRA), available at: http: //www.fao.org/forestry/fra/en/, 2012b.

Gaillard, M.-J., Sugita, S., Mazier, F., Trondman, A.-K., Broström, A., Hickler, T., Kaplan, J. O., Kjellström, E., Kokfelt, U., Kuneš, P., Lemmen, C., Miller, P., Olofsson, J., Poska, A., Rundgren, M., Smith, B., Strandberg, G., Fyfe, R., Nielsen, A. B., Ale- 
nius, T., Balakauskas, L., Barnekow, L., Birks, H. J. B., Bjune, A., Björkman, L., Giesecke, T., Hjelle, K., Kalnina, L., Kangur, M., van der Knaap, W. O., Koff, T., Lagerås, P., Latałowa, M., Leydet, M., Lechterbeck, J., Lindbladh, M., Odgaard, B., Peglar, S., Segerström, U., von Stedingk, H., and Seppä, H.: Holocene land-cover reconstructions for studies on land coverclimate feedbacks, Clim. Past, 6, 483-499, doi:10.5194/cp-6483-2010, 2010.

Gerard, F., Petit, S., Smith, G., Thomson, A., Brown, N., Manchester, S., Wadsworth, R., Bugar, G., Halada, L., Bezak, P., Boltiziar, M., De Badts, E., Halabuk, A., Mojses, M., Petrovic, F., Gregor, M, Hazeu, G., Mucher, C. A., Wachowicz, M., Huitu, H., Tuominen, S., Kohler, R., Olschofsky, K., Ziese, H., Kolar, J., Sustera, J., Luque, S., Pino, J., Pons, X., Roda, F., Roscher, M., and Feranec, J.: Land cover change in Europe between 1950 and 2000 determined employing aerial photography, Progr. Phys. Geogr., 34, 183-205, doi:10.1177/0309133309360141, 2010.

Hansen, M., DeFries, R., Townshend, J., and Sohlberg, R.: UMD Land Cover Classification,, available at: http://www.glcf.umd. edu/data/landcover/, 1998.

Hansen, M. C., DeFries, R. S., Townshend, J., and Sohlberg, R.: Global land cover classification at $1 \mathrm{~km}$ spatial resolution using a classification tree approach, Int. J. Remote Sens., 21, 13311364, 2000.

Herold, M. and DiGregorio, A.: Evaluating land-cover legends using the UN land-cover classification system, in Remote Sensing of Land Use and Land Cover: Principles and Applications, edited by: Giri, C., CRC Press, South Dakota, USA, p. 477, 2012.

Houghton, R. and Hackler, J.: Carbon flux to the atmosphere from land-use changes: 1850 to 1990 , ORNL/CDIAC-131, NDP-050/ R, 74, doi:10.3334/CDIAC/lue.ndp050, 2001.

Houghton, R. A., House, J. I., Pongratz, J., van der Werf, G. R., DeFries, R. S., Hansen, M. C., Le Quéré, C., and Ramankutty, N.: Carbon emissions from land use and land-cover change, Biogeosciences, 9, 5125-5142, doi:10.5194/bg-9-5125-2012, 2012.

House, J. and Prentice, I. C.: Maximum impacts of future reforestation or deforestation on atmospheric $\mathrm{CO}_{2}$, Glob. Change Biol., 8, 1047-1052, doi:10.1046/j.1365-2486.2002.00536.x, 2002.

Hurtt, G. C., Frolking, S., Fearon, M. G., Moore, B., Shevliakova, E., Malyshev, S., Pacala, S. W., and Houghton, R. A.: The underpinnings of land-use history: three centuries of global gridded land-use transitions, wood-harvest activity, and resulting secondary lands, Glob. Change Biol., 12, 1208-1229, doi:10.1111/j.1365-2486.2006.01150.x, 2006.

Intergovernmental Panel on Climate Change (IPCC): Good Practice Guidance for Land Use, Land-Use Change and Forestry, edited by: Penman, J., Gytarsky, M., Hiraishi, T., Krug, T., Kruger, D., Pipatti, R., Buendia, L., Miwa, K., Ngara, T., Tanabe, K., and Wagner, F.: Institute for Global Environmental Strategies (IGES) for the IPCC, Kanagawa, Japan, 2003.

Kaplan, J. O., Krumhardt, K. M., and Zimmermann, N.: The prehistoric and preindustrial deforestation of Europe, Quaternary Sci. Rev., 28, 3016-3034, doi:10.1016/j.quascirev.2009.09.028, 2009.

Klein Goldewijk, K., Beusen, A., and Janssen, P.: Long-term dynamic modeling of global population and built-up area in a spatially explicit way: HYDE 3.1, The Holocene, 20, 565-573, doi:10.1177/0959683609356587, 2010.
Klein Goldewijk, K., Beusen, A., Van Drecht, G., and De Vos, M.: The HYDE 3.1 spatially explicit database of human-induced global land-use change over the past 12,000 years, Global Ecol. Biogeogr., 20, 73-86, doi:10.1111/j.1466-8238.2010.00587.x, 2011.

Kuemmerle, T., Radeloff, V. C., Perzanowski, K., and Hostert, P.: Cross-border comparison of land cover and landscape pattern in Eastern Europe using a hybrid classification technique, Remote Sens. Environ., 103, 449-464, doi:10.1016/j.rse.2006.04.015, 2006.

Kuemmerle, T., Müller, D., Griffiths, P., and Rusu, M.: Land use change in Southern Romania after the collapse of socialism, Reg. Environ. Change, 9, 1-12, doi:10.1007/s10113-008-0050z, 2009.

Lahmeyer, J.: Population Statistics, available at: http://www. populstat.info/, 2006.

Mander, U. and Kuuba, R.: Changing landscapes in Northeastern Europe based on examples from the Baltic countries, in The New Dimensions of the European Landscapes, edited by: Jongman, R. H., pp. 123-134, Springer, available at: http://books.google.com/books?hl=enandamp;lr=andamp;id= F43tHLBnZeMCandamp;oi=fndandamp;pg=PA123andamp; $\mathrm{dq}=$ Changing + landscapes + in + Northeastern+Europe+based + on+examples+from+the+Baltic+countriesandamp;ots= vyuiFpdjhhandamp;sig=ZowGhLnWJc55_2DTqhDB12KhmuU (last access: 18 June 2012), 2004.

Maucha, G. and Buettner, G.: Validation of the European CORINE Land Cover 2000 database, in 25th EARSeL Symposium on Global Developments in Environmental Earth Observation from Space, pp. 449-457, Millpress, Porto, Portugal, available at: http://www.earsel.org/symposia/2005-symposium-Porto/pdf/ 055.pdf (last access: 18 June 2012), 2005.

Meissner, F.: Agrarian Reform in Sweden, J. Agr. Econom., 4, 444456, doi:10.1111/j.1477-9552.1956.tb02285.x, 1956.

Mueller, D., Kuemmerle, T., Rusu, M., and Griffiths, P.: Lost in transition?: determinants of post-socialist cropland abandonment in Romania, J. Land Use Sci., 4, 109-129, 2009.

Olofsson, J. and Hickler, T.: Effects of human land-use on the global carbon cycle during the last 6,000 years, Veg. Hist. Archaeobot., 17, 605-615, doi:10.1007/s00334-007-0126-6, 2008.

Orczewska, A.: Age and Origin of Forests in South-western Poland and their Importance for Ecological Studies in Man-dominated Landscapes, Landscape Res., 34, 599-617, doi:10.1080/01426390903184579, 2009.

Ozols, A.: Forests and Forestry in Latvia, in FAO/AUSTRIA SEMINAR ON THE ECONOMICS AND MANAGEMENT OF FOREST OPERATIONS FOR COUNTRIES IN TRANSITION TO MARKET ECONOMIES, pp. 1-191, FAO/Austria, Gmunden/Asutria, available at: http://www.fao.org/docrep/w3722E/w3722e21.htm\#TopOfPage, 1995.

Petit, C. and Lambin, E.: Long-term land-cover changes in the Belgian Ardennes (1775 \pm 1929): model-based reconstruction vs. historical maps, Glob. Change Biol., 8, 616-630, 2002.

Pinto-Correia, T. and Vos, W.: Multifunctionality in Mediterranean landscapes: past and future, in: The New Dimensions of the European Landscapes, edited by: Jongman, R. H., Springer, pp. 135-164, 2004. 
Poeplau, C., Don, A., Vesterdal, L., Leifeld, J., Van Wesemael, B., Schumacher, J., and Gensior, A.: Temporal dynamics of soil organic carbon after land-use change in the temperate zone - carbon response functions as a model approach, Glob. Change Biol., 17, 2415-2427, doi:10.1111/j.1365-2486.2011.02408.x, 2011.

Pongratz, J., Reick, C., Raddatz, T., and Claussen, M.: A reconstruction of global agricultural areas and land cover for the last millennium, Global Biogeochem. Cy., 22, 1-16, doi:10.1029/2007GB003153, 2008 .

Pontius, R. G., Boersma, W., Castella, J.-C., Clarke, K., Nijs, T., Dietzel, C., Duan, Z., Fotsing, E., Goldstein, N., Kok, K., Koomen, E., et al.: Comparing the input, output, and validation maps for several models of land change, Ann. Regional Sci., 42, 11-37, doi:10.1007/s00168-007-0138-2, 2008.

Prentice, I., Farquhar, G., and Fasham, M.: The carbon cycle and atmospheric carbon dioxide, in: Climate change 2001: the scientific basis: contribution of Working Group I to the Third Assessment Report of the Intergouvernmental Panel on Climate Change, edited by: Houghton, J. T., pp. 183-237, Cambridge University Press, Cambridge, available at: http://ir.anet.ua.ac.be/ irua/handle/10067/381670151162165141 (last access: 18 June 2012), 2001.

Prishchepov, A. V, Radeloff, V. C., Baumann, M., Kuemmerle, T., and Müller, D.: Effects of institutional changes on land use: agricultural land abandonment during the transition from state-command to market-driven economies in post-Soviet Eastern Europe, Environ. Res. Lett., 7, 024021, doi:10.1088/17489326/7/2/024021, 2012.

Ramankutty, N. and Foley, J. A.: Estimating historical changes in global land cover: Croplands from 1700 to 1992, Global Biogeochem. Cy., 13, 997-1027, 1999.

Rounsevell, M. D. A., Reginster, I., Araújo, M. B., Carter, T. R., Dendoncker, N., Ewert, F., House, J. I., Kankaanpää, S., Leemans, R., Metzger, M. J., Schmit, C., Smith, P., and Tuck, G.: A coherent set of future land use change scenarios for Europe, Agr. Ecosyst. Environ., 114, 57-68, doi:10.1016/j.agee.2005.11.027, 2006

Royal Swedish Academy of Agriculture and Forestry (KSLA): The Swedish Forestry Model, Stockholm, available at: http://www.skogsstyrelsen.se/Global/myndigheten/ Skogochmiljo/ENGLISH/retrieve_file.pdf, 2009.

Schulp, C. J. E. and Verburg, P. H.: Effect of land use history and site factors on spatial variation of soil organic carbon across a physiographic region, Agr. Ecosyst. Environ., 133, 86-97, doi:10.1016/j.agee.2009.05.005, 2009.
Schulze, E. D., Ciais, P., Luyssaert, S., Schrumpf, M., Janssens, I. A., Thiruchittampalam, B., Theloke, J., Saurat, M., Bringezu, S., Lelieveld, J., Lohila, A., Rebmann, C., Jung, M., Bastviken, D., Abril, G., Grass, G., Leip, A., Freibauer, A., Kutsch, W., Don, A., Nieschulze, J., Boerner, A., Gash, J. H., and Dolman, A. J.: The European carbon balance, Part 4: integration of carbon and other trace-gas fluxes, Glob. Change Biol., 16, 1451-1469, doi:10.1111/j.1365-2486.2010.02215.x, 2010.

Verburg, P. H. and Overmars, K. P.: Combining top-down and bottom-up dynamics in land use modeling: exploring the future of abandoned farmlands in Europe with the Dyna-CLUE model, Landscape Ecol., 24, 1167-1181, doi:10.1007/s10980009-9355-7, 2009.

Verburg, P., Rounsevell, M., and Veldkamp, A.: Editorial. Scenario based studies of future land use in Europe, Agr. Ecosyst. Environ., 114, 1-6, 2006.

Verburg, P. H., Eickhout, B., and Meijl, H.: A multi-scale, multimodel approach for analyzing the future dynamics of European land use, Ann. Regional Sci., 42, 57-77, doi:10.1007/s00168 007-0136-4, 2008

Verburg, P. H., Berkel, D. B., Doorn, A. M., Eupen, M., and Heiligenberg, H. a. R. M.: Trajectories of land use change in Europe: a model-based exploration of rural futures, Landscape Ecol., 25 , 217-232, doi:10.1007/s10980-009-9347-7, 2010.

Verburg, P. H., Neumann, K., and Nol, L.: Challenges in using land use and land cover data for global change studies, Glob. Change Biol., 17, 974-989, 2011.

Verburg, P. H., Asselen, S., Zanden, E. H., and Stehfest, E.: The representation of landscapes in global scale assessments of environmental change, Landscape Ecol., doi:10.1007/s10980-0129745-0, 2012.

Van der Werf, G. R., Morton, D. C., DeFries, R. S., Olivier, J. G. J., Kasibhatla, P. S., Jackson, R. B., Collatz, G. J., and Randerson, J. T.: $\mathrm{CO}_{2}$ emissions from forest loss, Nat. Geosci., 2, 737-738, 2009.

Van Eetvelde, V. and Antrop, M.: Analyzing structural and functional changes of traditional landscapes-two examples from Southern France, Landscape Urban Plan., 67, 79-95, 2004.

Van Eetvelde, V. and Antrop, M.: Indicators for assessing changing landscape character of cultural landscapes in Flanders (Belgium), Land Use Policy, 26, 901-910, doi:10.1016/j.landusepol.2008.11.001, 2009. 